\title{
Compressibility of foundation fills
}

\section{J. A. Charles and H. D. Skinner}

\section{N. A. Trenter, Fellow}

The authors provide useful data which will assist designers considering the possibility of collapse settlement (compression) in tills and colliery discards.

The plasticity indices are only given for some of the materials tested. Would the authors agree that the susceptibility of a fill to collapse settlement also depends upon its plasticity characteristics, all other factors remaining equal?

One of the most difficult decisions facing the designer of a major backfill is the level of compactive effort to select during compaction. Too high a compactive effort and there will be waste and unfriendly environmental consequences; too little and the possibility of significant collapse settlement becomes very real. The authors provide results (Figs 9 and 10) for two discard samples (A and B) from the same colliery in the English Midlands, tested under applied stresses of 30 and $60 \mathrm{kN} / \mathrm{m}^{2}$. The authors state that despite the differences in the stresses, very similar values of collapse settlement (measured as strains) were obtained.

This is indeed surprising: most designers would expect that the larger the confining stress, the larger the resulting collapse settlement. Hence, larger collapse settlement would have been expected for the sample tested under 60 than under $30 \mathrm{kN} / \mathrm{m}^{2}$. The influence of vertical stress on the magnitude of collapse settlement for a colliery discard, also from the English Midlands, was investigated in the laboratory by Blanchfield and Anderson ${ }^{36}$ who found that a relationship was clearly established (their Fig 5). In such circumstances, there would be an infinite number of relationships of the sort shown in the authors' Figs 9 and 10, depending upon the confining stresses.

It would be helpful if the authors could clarify the influence of vertical stress on the magnitude of collapse settlement for colliery discards and other materials. It would seem that the similar results obtained by the authors for the two confining stresses in their tests could be due to the fact that two different discard samples were employed, unlike the Blanchfield and Anderson test series where only one was adopted. The differences in the nature of the discard in the two samples could have masked the otherwise to be expected dependence of collapse settlement on applied stress. In this connection, it is noted that there were substantially more fines in sample B as tested by the authors than in sample A.
Authors' reply

The authors wish to thank the discusser for his comments on their paper. He has raised important issues, particularly the stress-dependency of collapse settlement.

The question of the dependency of collapse settlement on the level of overburden stress has been highlighted in relation to mudstone backfills by Blanchfield and Anderson ${ }^{36}$ and in the subsequent discussion by Charles and Skinner. ${ }^{37}$ When testing samples of mudstone fill, obtained by breaking up the parent mudstone, Blanchfield and Anderson found that collapse compression increased as the applied vertical stress on inundation increased from 100 to $700 \mathrm{kPa}$. The samples had a very low fines content, high air voids and low moisture content.

In contrast to the test results described by Blanchfield and Anderson, the authors found no significant increase in collapse compression for samples of a colliery spoil tested at low moisture content and inundated over a range of applied vertical stress from 40 to $120 \mathrm{kPa}$. This is shown in Fig. 8 of the paper and the data are replotted in Fig. 16 to show collapse compression as a function of applied stress. The same behaviour is illustrated in Fig. 17(a) which shows the

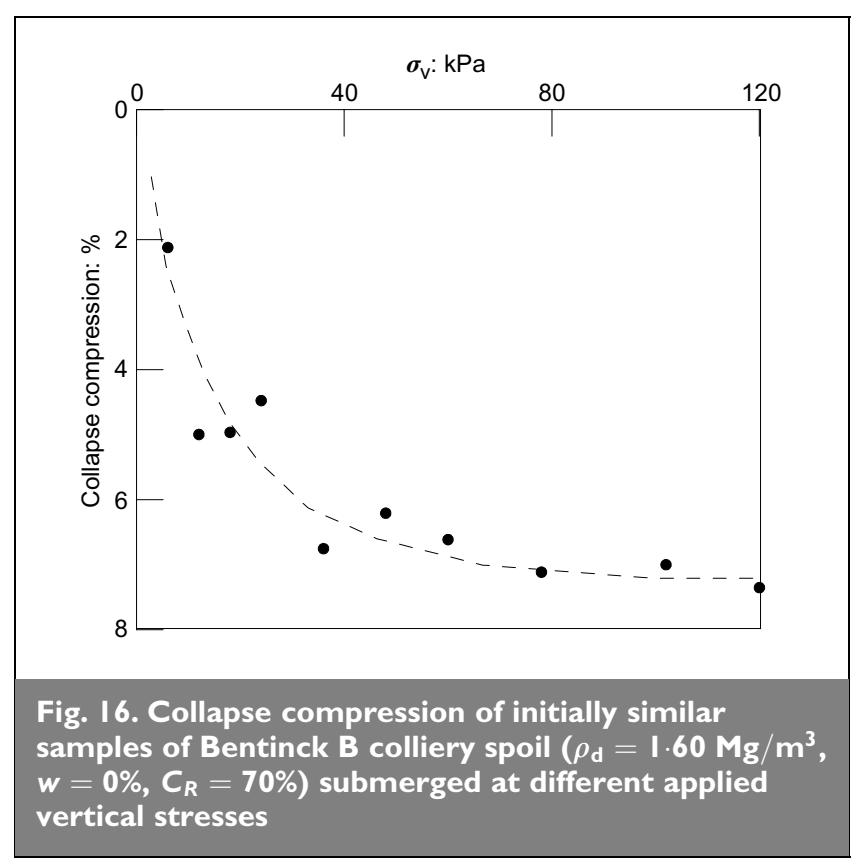




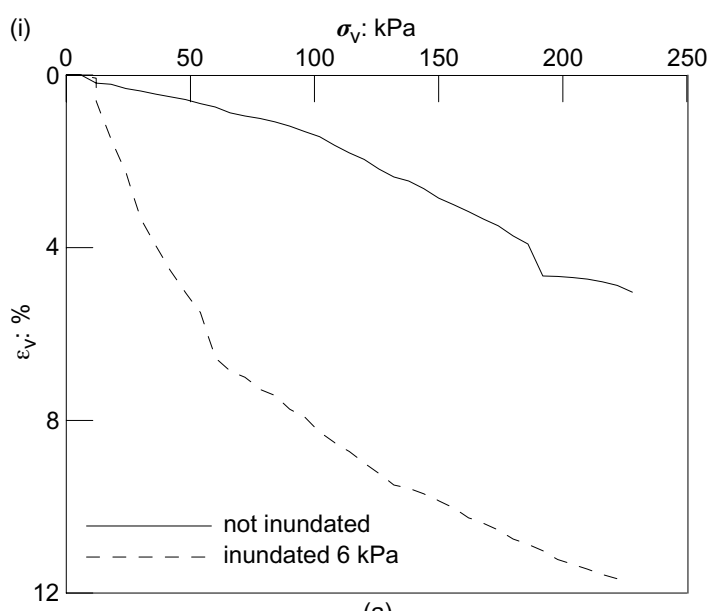

(a)

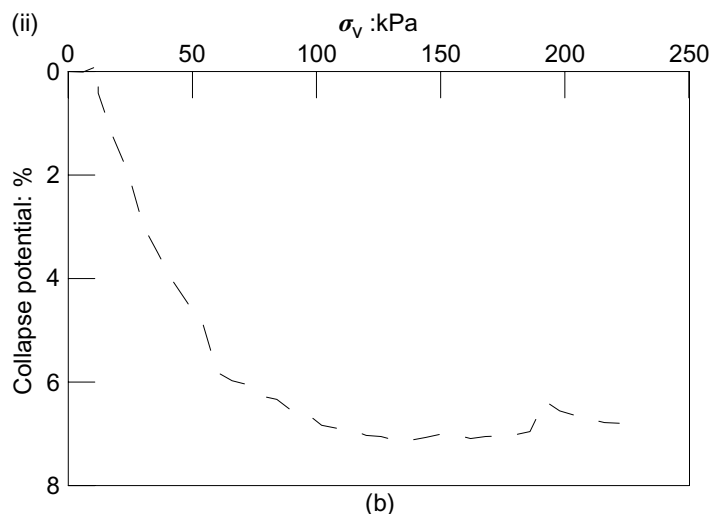

(b)

Fig. 17. One-dimensional compression of Bentinck B colliery spoil samples with $w=8 \%, C_{R}=83 \%$ (i) double oedometer results; (ii) collapse potential

compression of two identical samples of colliery spoil placed at a moisture content near optimum. The collapse potential at a particular applied stress, plotted in Fig. 17(b), is given by the difference between the compression of the sample which was inundated at $6 \mathrm{kPa}$ and the sample which was not inundated. ${ }^{38}$ Collapse potential increased markedly up to a vertical stress of $60 \mathrm{kPa}$. There was a small further increase up to an applied vertical stress of $130 \mathrm{kPa}$, above which there was a slight decrease. Field measurements of the collapse compression of an opencast mudstone and sandstone backfill at Horsley ${ }^{39}$ show a similar result; above some stress level there is no discernible trend of increase in collapse with increased applied vertical stress.

Modellers of partially saturated soil behaviour have found that there exists some stress at which a maximum collapse is found. ${ }^{39,40}$ At very low values of applied vertical stress, there is no collapse on inundation, and at very high confining pressures collapse is suppressed. It may be questioned whether between these two extremes there is some range of stress where there is little variation in collapse settlement with applied vertical stress. For the two colliery spoils tested by the authors this was the case.

The colliery spoil fills tested by the authors were predominantly formed from weak mudstones and siltstones.
Similarly the fill tested by Blanchfield and Anderson was a mudstone fill. Vaughan ${ }^{41}$ distinguished between the gradings of fills of weak rocks formed by, respectively, blasting and ripping. Typically, the former process produces an open structure with few fines, with highly stressed contacts between large particles. The latter process tends towards a more dense packing, with the larger particles separated by fines and with more numerous and lightly stressed contacts. The former packing is described as 'underfilled' and the latter 'filled'. The behaviour of the two types of fill is different. A weak mudstone sample that tends towards a filled grading is likely to exhibit at relatively low applied vertical stress a maximum reduction in void ratio that can be developed during collapse compression. In contrast, an underfilled grading will have the capacity, even at much higher applied vertical stresses, to show an increasing reduction in void ratio as the stress increases. The samples tested by the authors contained between 10\% and 20\% fines before compaction, compared with less than 5\% initial fines content of samples tested by Blanchfield and Anderson. The difference between the results of Blanchfield and Anderson and those measured in the field and in laboratory tests reported by the authors may be largely attributable to this fundamental difference in grading.

The discusser notes that plasticity of the fines content was quoted for only two of the four fills described in the paper. It was considered that for the two granular fills, which both had less than $20 \%$ fines content, this was not a helpful parameter. The plasticity of a more clayey fill will have a significant impact on the optimum water content, and is likely to strongly influence the compaction characteristics. None of the testing reported in the paper can, however, indicate the extent to which plasticity will govern collapse potential.

In conclusion, it is emphasised that the magnitude of collapse settlement has been found by the authors and others to depend on a large number of factors including fill type, water content, water content history, compaction, compacted structure and suction, as well as the value of applied vertical stress. It seems simplistic to focus primarily on an assumed variation with applied vertical stress, which in many situations may not have the greatest influence on the final magnitude of collapse settlement. If a compaction regime is being designed for a major backfill, it would be prudent to confirm experimentally the likely collapse settlement over the range of overburden stresses to be found in the field, rather than to extrapolate from laboratory tests carried out at a higher or lower applied vertical stress.

\section{REFERENCES}

36. Blanchfield R. and Anderson W. F. Wetting collapse in opencast coalmine backfill. Proceedings of Institution of Civil Engineers Geotechnical Engineering, 2000, 143, No. 3, July, 139-149.

37. Charles J. A. and Skinner H. D. Discussion: Wetting collapse in opencast coalmine backfill. Proceedings of the Institution of Civil Engineers Geotechnical Engineering, 2001, 149, No. 2, April, 129-130.

38. Jennings J. E. and KNight K. The additional settlement of foundations due to a collapse of structure of sandy subsoils on wetting. Proceedings of the 4th International 
Conference on Soil Mechanics and Foundation Engineering, London, 1957, 1, 316-319.

39. Alonso E. E., Gens A. and Hight D. W. Special problem soils: general report. Proceedings of the 9th European Conference on Soil Mechanics and Foundation Engineering, Dublin, 1987, 3, 1087-1146.

40. Lawton E. C., Fragaszy R. J. and Hardcastle J. H.
Collapse of a compacted clayey sand. ASCE Journal of Geotechnical Engineering, 1989, 115, No. 9, 1252-1267.

41. Vaughan P. R. Criteria for the use of weak and weathered rock for embankment fill, and its compaction control. Proceedings of the 13th International Conference on Soil Mechanics and Foundation Engineering, New Delhi, 1994, 6, 195-206. 